\title{
Impacts of common staff on indicators of sanitary evacuation: experience of the gynecology service of Treichville Teaching Hospital
}

\author{
Simplice Anongba, Jean-Marc Dia, Ignace Yao*, Edouard N'guessan, \\ Eric Bohoussou, Privat Guié
}

Department of Gynecology and Obstetrics, Treichville Teaching Hospital Abidjan, Côte d'Ivoire

Received: 24 January 2018

Accepted: 28 February 2018

\section{*Correspondence:}

Dr. Ignace Yao,

E-mail: yaoignacen@yahoo.fr

Copyright: (C) the author(s), publisher and licensee Medip Academy. This is an open-access article distributed under the terms of the Creative Commons Attribution Non-Commercial License, which permits unrestricted non-commercial use, distribution, and reproduction in any medium, provided the original work is properly cited.

\section{ABSTRACT}

Background: In order to improve the quality of care for patients discharged in our department, since 1996 we have initiated monthly meetings called "common staffs", with the heads of the peripheral maternities who evacuate patients, during which we analyse reference indicators and the SONUs. The objective of this study was to describe the impact of the common staff on the indicators of the reference.

Methods: We carried out a retrospective cross-sectional study on the balance sheets of the common staff over the 20 years of practice.

Results: In 20 years, 132 meetings were organized, during which 24,337 files were analyzed. In 1996 the indicators of evacuations were at alarming levels: the time taken between the diagnosis and the decision to evacuate was long (more than 1 hour in $83.4 \%$ ), $73 \%$ of the evacuation records were poorly informed, the majority evacuations were by non-medical vehicle $(54.8 \%)$, pre-discharge management was incorrect in several patients $(47 \%)$, and maternal and fetal lethality were high (5\% and $10 \%$, respectively). Over time, these indicators have improved and have had a favourable impact on maternal and fetal mortality rates, which have gradually decreased. At the same time, the results of the last three years of the evacuees coming from the maternities who do not participate in our staffs, shows that the indicators are still alarming, at levels where we were at the beginning of common staffs.

Conclusions: The joint staff proved to be a good practice to promote in the Gynecology and Obstetrics Departments. It helped to improve the quality of care for referred patients.

Keywords: Common staff, Dysfunctioning, Quality, Reference

\section{INTRODUCTION}

In developing countries, the organization of obstetric evacuations has a real problem with preventable morbidities and maternal-fetal deaths. In Côte d'Ivoire in particular, the maternal death rate is very high with 612 deaths for 100000 live births. ${ }^{1}$ There is no control system between the reference centers and peripheral maternities (which evacuate the patients), making it possible to coordinate and improve obstetric evacuation. So before 1996, there was no consultation between the reference maternity CHU Treichville and peripheral maternities its coverage area (peripheral maternity south of Abidjan). The patients were frequently evacuated under inadequate conditions and very often arrived in an aggravated state, related to the initial poor management and the dysfunction in their evacuation. ${ }^{2,3}$

To improve the quality of evacuations, our service has initiated since 1996 monthly meetings called "common staffs," with leaders of outlying maternity Abidjan South. During these joint staff, evacuation indicators are analyzed as well as the assessment of obstetric and neonatal care (SONU) provided to evacuees. We 
conducted this study on the assessment of these various joint staff with the aim of describing the positive effects of these common staff on evacuation indicators, and to identify weak points to improve.

\section{METHODS}

We conducted a retrospective and descriptive crosssectional study in the Gynecology and Obstetrics Department of the CHUT, focusing on the annual report of the common staff from 1996 to 2015 (20 years).

The parameters analyzed were the mode of evacuation, the state of the evacuation cards, the delays of management, the diagnostic concordance, the initial care of the patients. The data was collected from the archives of our audit unit on the balance sheet of the common staffs.

\section{Organization of common staff}

A common staff has been held monthly since January 1996 between the caretakers of the gynecology and obstetrics department of the CHUT (reference center) and those of the peripheral maternity units in South Abidjan (maternity hospital dependent on the health coverage area of the CHUT). Over the 12 months of the year, there are 11 staffs, the last month being devoted to holidays. During this staff, the evacuation indicators are analyzed in the patients evacuated by these maternities to the CHUT, the previous month. This audit concerned the initial care at the maternity center, the conditions of the transfer and the care in our service.

At the end of the year an annual common staff is organized making an assessment of analyses of monthly common staffs made during year.

Besides we receive sometimes very often from evacuees coming from maternities outside the zone of South
Abidjan (that we call collectively maternities out of area) for diverse reasons. Since 2013, we analyze during our common staffs, the indicators of the evacuations of these patients (although the doctors of these maternities out of area do not participate in our common staffs), to compare them with the indicators of the evacuees coming from maternity hospitals of our area.

\section{RESULTS}

\section{Frequency of common staffs}

132 meetings were organized, at the rate of 6 meetings on average a year with extremes from 2 to 10 .

\section{Status of indicators in 1996 and 2015}

In Table 1, we see the positive evolution of the indicators between the beginning of the common staffs in 1996 and the time of the study in 2015 .

Table 1: Rate of indicators (in percentage) at the beginning and at the end of the study.

\begin{tabular}{|c|c|c|}
\hline Indicators & 1996 & 2015 \\
\hline $\begin{array}{l}\text { Deadline between the diagnosis and } \\
\text { the decision to evacuate }>1 \text { hour }\end{array}$ & 83.4 & 15.8 \\
\hline Evacuation by not medical vehicles & 54.8 & 34.4 \\
\hline $\begin{array}{l}\text { Bad holding of the index forms of } \\
\text { evacuation }\end{array}$ & 73 & 12 \\
\hline Diagnostic discordance & 36.3 & 8.8 \\
\hline Incorrect care before the evacuation & 47 & 7 \\
\hline Maternal lethality of the referred & 5 & 0.3 \\
\hline fetal lethality & 1 & 3.5 \\
\hline
\end{tabular}

\section{Evolution of the rates of indicators during the period of study}

The following three figures appreciate the evolution of dysfunctionment year by year from 1996 to 2015 .

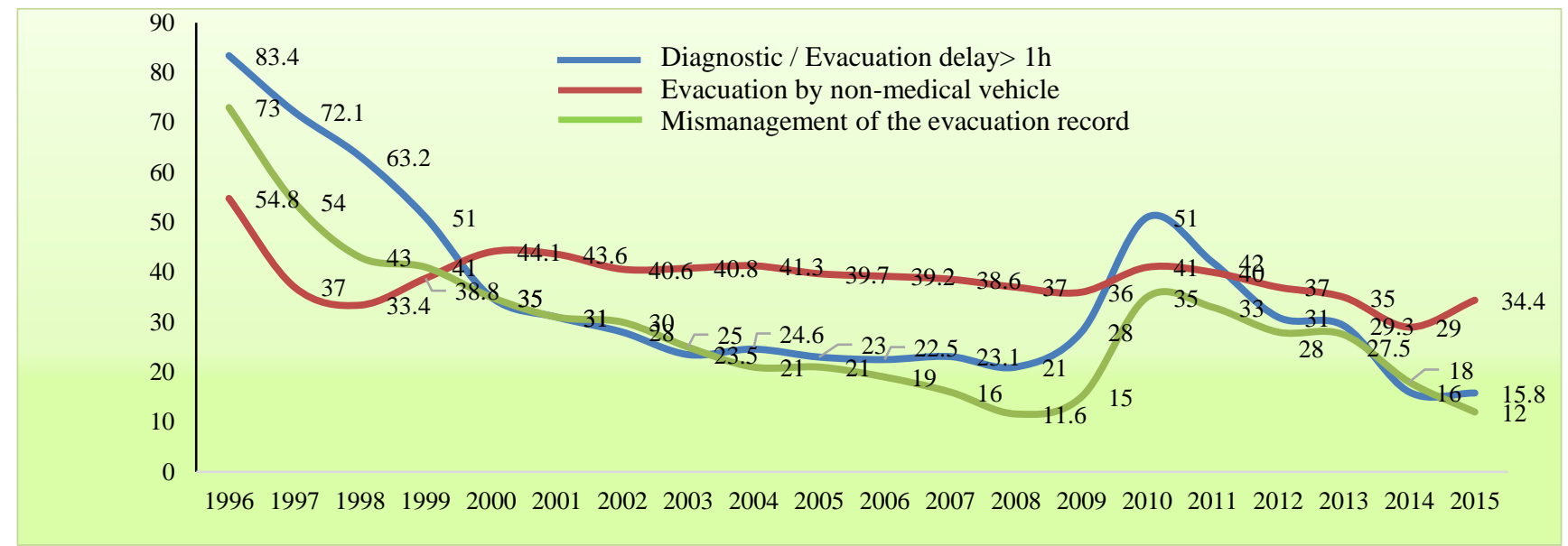

Figure 1: Evolution of the indicators of the mode of evacuation from 1996 to 2015. 
The delays between the time of diagnosis and the evacuation of the patient who was more than $1 \mathrm{~h}$ in $83.4 \%$ in 1996 rose to $15.8 \%$ in 2015
The discordant diagnoses are from $36.3 \%$ to $8.8 \%$ from 1996 to 2015. Maternal and fetal lethality increased respectively from 5 to 0.3 and from 10 to 3.5 , from 1996 to 2015 .

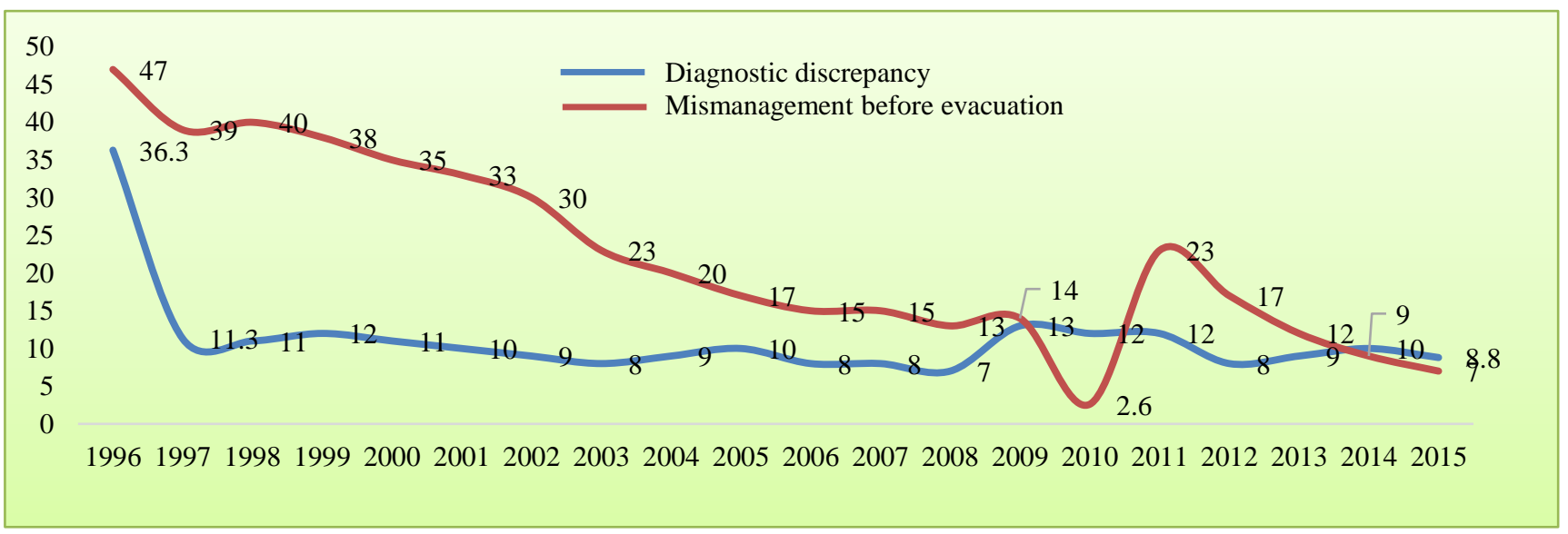

Figure 2: Evolution of the indicators of the initial care in the peripheral maternities between 1996 and 2015.

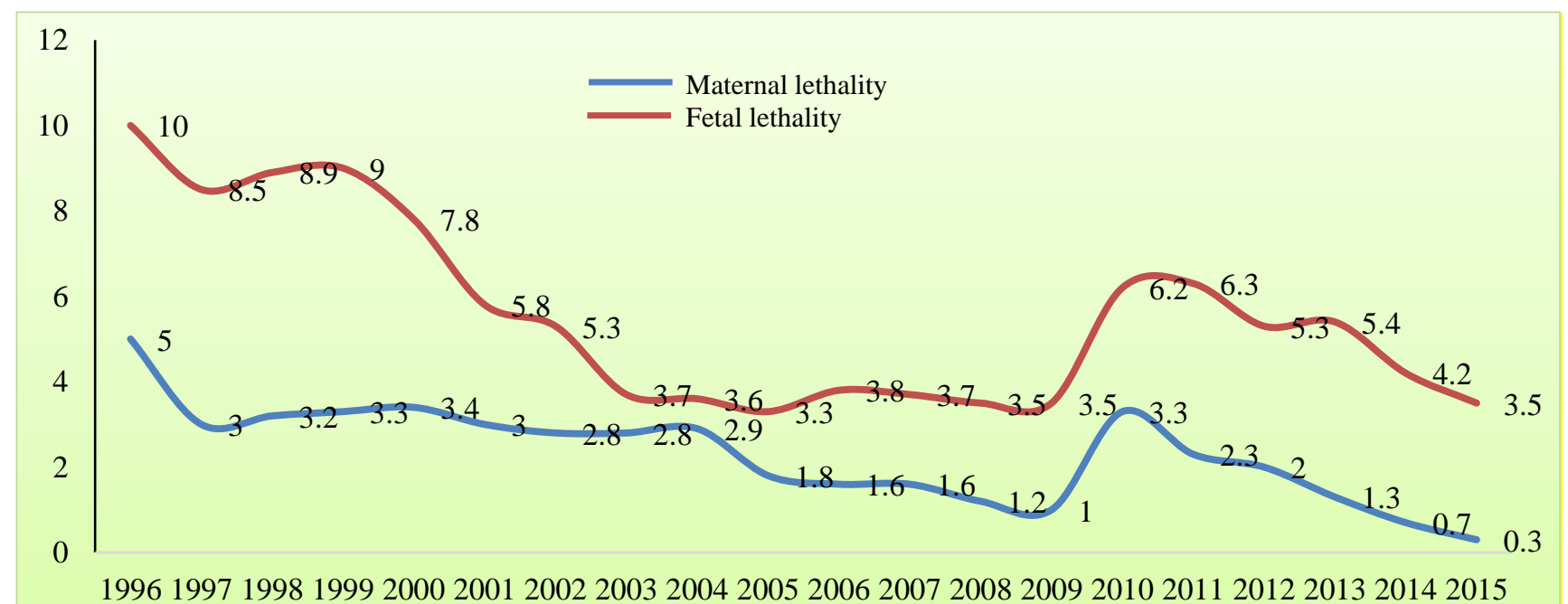

Figure 3: Evolution of materno-fetal mortality indicators among evacuees from 1996 to $2015 . s$

Table 2: The annual rates of indicators (in percentage) according to the zone of evacuation during 2013, 2014 and 2005.

\begin{tabular}{|lllllll|}
\hline & $\begin{array}{l}2013 \\
\text { Maternities } \\
\text { off area }\end{array}$ & $\begin{array}{l}\text { Maternities } \\
\text { South Abidjan }\end{array}$ & $\begin{array}{l}\text { Maternities } \\
\text { off area }\end{array}$ & $\begin{array}{l}\text { Maternities Sol } \\
\text { Abidjan }\end{array}$ & $\begin{array}{l}\text { Maternities } \\
\text { off area }\end{array}$ & $\begin{array}{l}\text { Maternities } \\
\text { South Abidjan }\end{array}$ \\
\hline $\begin{array}{l}\text { Indicators } \\
\begin{array}{l}\text { Evacuation by not } \\
\text { medical vehicles }\end{array}\end{array}$ & 31 & 35 & 30 & 29 & 33 & 34.4 \\
\hline $\begin{array}{l}\text { Bad holding of the inde } \\
\text { forms of evacuation }\end{array}$ & 90 & 27.5 & 91 & 18 & 85 & 12 \\
\hline $\begin{array}{l}\text { Diagnostic discordance } \\
\text { Incorrect care before }\end{array}$ & 22 & 9 & 23 & 10 & 25 & 8.8 \\
\hline $\begin{array}{l}\text { the evacuation } \\
\text { Maternal lethality }\end{array}$ & 42 & 12 & 49 & 9 & 48 & 7 \\
\hline Fetal lethality & 13 & 1.3 & 3 & 0.7 & 2.1 & 0.3 \\
\hline
\end{tabular}




\section{Comparison of indicators according to the area of evacuation}

The comparison of the indicators of the various maternities of the years 2013, 2014 and 2015 showed that the indicators of the maternities participating in common staffs were clearly better than those of the maternities (maternity hospitals) except (off) zones. The results are summarized in Table 2.

\section{DISCUSSION}

\section{Frequency of common staffs}

In 20 years, 132 meetings were organized, at the rate of 6 staffs on average a year with extremes from 2 to 10 . The holding of these staffs knew some difficulties which we nevertheless surmounted. Indeed, the implementation of common staffs in 1996 was characterized by a lack of membership of some of our partners of the peripheral maternity hospitals but over time we were able to obtain the participation of the persons in charge of all the peripheral maternity hospitals. Besides between 2000 and 2011 our country knew periods of politico-military crises, preventing the regular holding of common staffs.

\section{State of indicators in 1996 and in 2015}

The report of common staffs of 1996 reflected the situation in which every structure organized its obstetric evacuations without established standards. This balance sheet (assessment) thus laid bare (stripped) the dysfunctions of our reference system, characterized by alarming indicators of the reference: the delay in the decision-making to evacuate once the composed diagnosis, was noticed at the majority of the patients [deadline (extension) upper at the 1 am in $83.3 \%$ ], as well as important rates of transfer by not medical vehicle (54.8\%), of diagnostic conflicts $(36.3 \%)$, and of incorrect coverage(care) before the evacuation (47\%). These dysfunctions had for consequence of the disturbing rates of lethality: $5 \%$ of mortality to mother and $10 \%$ in fetus.

In 2015 , the situation was very different with a clear (net) improvement of the various indicators with the exception of the rate of transfer by vehicles not provided with medical care which did not vary in a significant way.

\section{Impact of common staffs on reference indicators}

\section{The positive effects of common staffs}

Over time the persons in charge of the peripheral maternities of our zone gradually adhered to the recommendations of our staffs, and from 1997, the balance sheet showed the first positive effects of these staffs on reference indicators. Over the years these indicators gradually improved until period 2010 - on 2011 when the situation slightly deteriorated with the military crisis of 2010 and 2011, which was for its peak.
During this period hospitals generally worked with difficulty and it was almost impossible to organize common staffs. But since 2012 everything is back to normal again and the balance sheets of the last 3 years showed a net improvement of reference indicators. Besides the comparison of the indicators of the various maternities of the years 2013, 2014 and 2015 showed that the indicators of the maternities participating in common staffs were clearly better than those of the maternities except zones. Thus, these various reports allow us to assert that common staffs had a positive impact on our reference system namely: a better holding of the index card of evacuation, an improvement of the rates of diagnostic concordance, an improvement of the coverage before the evacuation, and a reduction in the mortality materno-fetale. This reduction in the maternal mortality in the evacuated patients brings back by Bohoussou and Yao in our service between 2005 and 2013.,5

\section{The not improved points}

Common staffs were not able to act on certain points of the reference such as the transfer by not medical vehicles. In effects patients' rates transferred by not medical vehicles always remained high (beyond 30\%) in spite of the recommendations of common staffs. The improvement of this indicator depends especially on the intervention of the state which endows the structures in ambulance. Indeed, several hospitals are not equipped in ambulance in our country, so delivering the sick to the not secure transport of the not medical vehicles. Transfers by not medical vehicles are common in number of our African countries and were reported in many publications. ${ }^{6-10}$

\section{CONCLUSION}

Present study has allowed us to state that it is possible to reduce the morbidity and mortality of patients discharged in our low-resource countries, thanks to some good practices such as the common staff. This practice must therefore be supported and popularized.

Funding: No funding sources Conflict of interest: None declared

Ethical approval: The study was approved by the Institutional Ethics Committee

\section{REFERENCES}

1. EDS-CI: Demographic Health Survey Côte d'Ivoire 2011-2012. Available

at: https://dhsprogram.com/pubs/pdf/FR272/FR272.pdf.

2. Bohoussou KPE. Maternal mortality in the maternity of the University Hospital of Treichville: About 203 cases (Abidjan, Cote d'Ivoire). Ann SOGGO. 2006;2(7):36-41.

3. Privat G, Eric B, Evelyne AA. Determinants of fetal intra-partum death at the maternity Hospital of the 
Chu of Treichville (Abidjan). Rev Int Sc Méd. 2007;9(2):66-9.

4. Bohoussou KPE, Guié P, Oyéladé M, N'guessan E, Anongba S, Coulibaly TK. Evolution of the maternal mortality in the maternity of the University Hospital of Treichville in Abidjan of 2005-2009. Newspaper of the SAGO. 2012;13(1):6-10.

5. Yao NI, Guié YP, Dia JM, Bohoussou PE, N'guessan KE, Saki CT, et al. Maternal mortality context of political free health care one pregnancy and birth to tea Treichville Teaching Hospital (Abidjan Côte d'Ivoire). Int J Reprod Contracept Obstet Gynecol. 2016;5(7):2333-7.

6. Cissé ML, Raad B, Diouf A, Wade F, Moreau JC. Balance sheet of the obstetric evacuations at the regional hospital of Kolda (Senegal). Med Afr Noire. 2010;5701:37-43.

7. Ekoundzola JR, Buambo SF, Nkihouabonga G. About 204 parturient referred on the Hospital and university Center of Brazzaville. Newspaper of the SAGO. 2003;4(2):1-5.

8. Sepou A, Goddot M, NGbale R, Gaunefetc CE, Domande M, Fandemae E, Baligross S. Evolution of the frequency and the problems were bound (connected) to the sanitary evacuations towards the department of gynecology-obstetrics of the community hospital of Bangui. Wink Mothers Child Health. 2009;6(1):1007-12.

9. Ouédraogo C, Zoungrana T, Dao B, Dujardin B, Ouédraogo A, Thieba B, et al. The quality Caesarean section to the hospital center Yalgado Ouagadougou of Ouagadougou. Obstetrics analyse determiners about 478 cases brought together in the Department of Gynecology. Med Afr Noir. 2001;48:443-50.

10. Lompo K, Hutin YJF, Traore G, Tall F, Guiardschmid JB. Morbidity and mortality bound to the sanitary evacuations of obstetrics at the hospital of Bobo-Dioulasso, Burkina Faso. Ann Belgian Society Tropical Med. 1993;73(2):153-63.

Cite this article as: Anongba S, Dia JM, Yao I, N'guessan E, Bohoussou E, Guié P. Impacts of common staff on indicators of sanitary evacuation: experience of the gynecology service of Treichville Teaching Hospital. Int J Reprod Contracept Obstet Gynecol 2018;7:1303-7. 